\title{
Low triiodothyronine (T3) state: a predictor of outcome in respiratory failure? Results of a clinical pilot study
}

\author{
Elvio Scoscia, Stefano Baglioni, Amir Eslami, Giorgio Iervasi ${ }^{1}$, Simonetta Monti ${ }^{1}$ and Tommaso Todisco \\ Pulmonary Institute and Respiratory Intensive Care Unit - R. Silvestrinì Hospital, Perugia, Italy and ${ }^{1}$ Clinical Physiology Institute of Research National \\ Council, Pisa, Italy \\ (Correspondence should be addressed to E Scoscia; Email: elvio.scoscia@libero.it)
}

\begin{abstract}
Background and aim: Various low triiodothyronine (T3) states have been described in severe nonthyroidal diseases and associated with a poor prognosis in cardiovascular disease patients. We assessed thyroid function in patients with severe respiratory failure from pulmonary disorders, and needing invasive or noninvasive mechanical ventilation, in order to evaluate the prognostic value of nonthyroidal illness syndrome.

Methods: We studied 32 consecutive patients with acute or acute-on-chronic respiratory failure. Measured variables upon admission included APACHE II score, the ratio of the partial pressure of oxygen in arterial blood to the fraction of oxygen in inspired gas $\left(\mathrm{PaO}_{2} / \mathrm{FiO}_{2}\right)$, and plasma levels of free T3 (fT3) and free thyroxine (fT4), and TSH levels. Thyroid function was further evaluated at discharge.

Results: Plasma levels of fT3 were below normal in 17 patients $(53 \%)$. Plasma fT3 was correlated with $\mathrm{PaO}_{2} / \mathrm{FiO}_{2}(P<0.001)$, and with APACHE II score $(P=0.003)$. In four patients $(12.5 \%)$ who died, fT3 levels were significantly lower $(P=0.002)$ than in patients who survived. In univariate logistic regression analysis, fT3 was the only factor significantly associated with an increased risk of death (odds ratio, 64.23; 95\% confidence interval, $1.78-2316.86, P=0.023$ ). Normalization of thyroid function was observed at discharge with a significant correlation between the percent increase in both fT3 and $\mathrm{PaO}_{2} / \mathrm{FiO}_{2}(P=0.015)$. $P$ values were calculated using Spearman's Correlation Coefficient.

Conclusion: Our preliminary data suggest that the low T3 state is a predictor of outcome in pulmonary patients with respiratory failure.
\end{abstract}

European Journal of Endocrinology 151 557-560

\section{Introduction}

Abnormal plasma levels of thyroid hormones have been reported in patients with a variety of nonthyroidal illnesses (1). Several conditions are described, the most important of which is the low T3 syndrome (2), which is characterized by reduced plasma levels of triiodothyronine (T3) due to impaired activity of specific $5^{\prime}$ monodeiodinases converting thyroxine (T4) to $\mathrm{T} 3$ in peripheral tissues (3). Circulating levels of T4 range from reduced to slightly elevated, with either normal or slightly suppressed thyroid-stimulating hormone (TSH) levels (3).

The low T3 state has been described in starvation (4), sepsis (5), surgery (6), myocardial infarction and heart failure $(7,8)$, cardiopulmonary bypass $(9)$, bone marrow transplantation (10) and any other severe illness (11).

To date, there are few data on thyroid function in patients with respiratory diseases due to pulmonary disorders (12-15), and there are no data available on thyroid function in respiratory failure patients needing invasive or noninvasive mechanical ventilation.
The aim of this study was to evaluate thyroid function in a group of patients with respiratory failure due to pulmonary disorders who were admitted to the respiratory intensive care unit of our institution. This study was approved by the ethics committee of our institution.

\section{Subjects and methods}

\section{Study population}

We evaluated 44 consecutive patients admitted to our respiratory intensive care unit because of acute or acute-on-chronic respiratory failure requiring mechanical ventilation. For the acquisition of data on pulmonary patients, 11 subjects were excluded because of intrinsic thyroid disorders (two patients) or comorbid conditions known to alter thyroid function (10 patients). Comorbid conditions included advanced congestive heart failure (two patients), recent myocardial infarction (two patients), acute pancreatitis (one patient), neurologic disorders (two patients) and renal failure (two patients). One further patient was excluded because of recent use of 
amiodarone, which may interfere with thyroid hormone metabolism. At the time of admission, the patients had received no therapy with drugs known to alter the thyroid function, such as corticosteroid, dopamine, aspirin, etc. The final study sample consisted of 32 patients, whose characteristics are reported in Table 1.

All patients were on oxygen therapy at the time of admission and were treated with mechanical ventilation. Oxygen was supplied by nasal prongs or through the ventilator circuit to achieve an arterial oxygen saturation of $\geq 92 \%$.

Intermittent negative pressure ventilation was used in 9 patients (28\%) via iron lung (Mod. C 900; Coppa Biella, Biella, Italy). Twenty-three patients $(72 \%)$ underwent positive pressure ventilation via a pressure-cycled ventilator in assist/control mode or pressure support mode. Positive end-expiratory pressure was applied when required, at a level of $4-5 \mathrm{cmH}_{2} \mathrm{O}$. Mechanical ventilation was performed by nasal or facial masks in 17 patients, and by endotracheal tube in 6 .

\section{Study protocol}

Clinical history and physical examination were performed in all patients at the time of admission. APACHE II score was also obtained (16). Arterial blood gases were measured, and the ratio of the partial pressure of oxygen in arterial blood to the fraction of oxygen in inspired gas $\left(\mathrm{PaO}_{2} / \mathrm{FiO}_{2}\right)$ was calculated.

Thyroid function was evaluated by measuring plasma levels of free T3 (fT3), free T4 (fT4), and TSH with a direct chemiluminescence assay (ADVIA, Bayer Health Care LLC Tarrytown, NY, USA) within $24 \mathrm{~h}$ of

Table 1 Characteristics of study population.

\begin{tabular}{|c|c|c|}
\hline \multirow[b]{2}{*}{ Age (years) } & \multicolumn{2}{|c|}{$\begin{array}{l}\text { Median (range), or } \\
\text { number }(\%)\end{array}$} \\
\hline & 75.5 & $(43-90)$ \\
\hline Sex (male) & 18 & $(56)$ \\
\hline \multicolumn{3}{|l|}{ Cause of respiratory failure } \\
\hline Chronic obstructive pulmonary disease & 23 & $(72)$ \\
\hline Pneumonia & 6 & (19) \\
\hline Pulmonary fibrosis & 3 & $(9)$ \\
\hline APACHE II score & 19 & $(11-29)$ \\
\hline \multicolumn{3}{|l|}{ Blood gases } \\
\hline $\mathrm{PaO}_{2}(\mathrm{mmHG})$ & 48 & $(23-115)$ \\
\hline $\mathrm{PaCO}_{2}(\mathrm{mmHG})$ & 78 & $(31-113)$ \\
\hline $\mathrm{PaO}_{2} / \mathrm{FiO}_{2}$ & 168 & $(63-271)$ \\
\hline \multicolumn{3}{|l|}{ Thyroid hormones } \\
\hline fT3 (pg/ml) & 2.33 & $(1.00-3.50)$ \\
\hline fT4 (ng/dl) & 1.29 & $(0.56-2.00)$ \\
\hline TSH $(\mu \mathrm{lU} / \mathrm{ml})$ & 0.63 & $(0.03-2.90)$ \\
\hline \multicolumn{3}{|l|}{ Metabolic parameters } \\
\hline Cholesterolemia (mg/dl) & 145 & $(70-291)$ \\
\hline Trigliceridemia (mg/dl) & 66.5 & $(49-248)$ \\
\hline Protidemia (gr/dl) & 7.25 & $(5.3-8.6)$ \\
\hline Glycemia (mg/dl) & 143 & $(73-198)$ \\
\hline Creatininemia (mg/dl) & 0.84 & $(0.61-2.49)$ \\
\hline
\end{tabular}

$\mathrm{PaO}_{2}$; partial pressure of oxygen, arterial.

$\mathrm{PaCO}_{2}$; partial pressure of carbon monoxide, arterial.

$\mathrm{FiO}_{2}$; fraction of oxygen in inspired gas. admission. According to the manufacturer's instructions, the normal range was $2.3-4.2 \mathrm{pg} / \mathrm{ml}$ for fT3, $0.8-1.76 \mathrm{ng} / \mathrm{dl}$ for $\mathrm{fT} 4$ and $0.35-5.5 \mu \mathrm{IU} / \mathrm{ml}$ for $\mathrm{TSH}$ (the analytic and functional sensitivity of the TSH was $0.004 \mu \mathrm{UI} / \mathrm{ml}$ ). Thyroid function was further evaluated upon discharge from the respiratory intensive care unit.

Routine blood tests were also obtained in order to exclude cachexia and/or any significant metabolic disorder which could alter thyroid hormone metabolism.

\section{Statistical analysis}

Data were reported as median and range. Continuous variables were compared by the nonparametric paired-samples Wilcoxon test or unpaired-samples Mann-Whitney test. Association between variables was assessed by Spearman's correlation coefficient. Univariate logistic regression was used to identify factors significantly associated with an increased risk of death; for each variable, the odds ratio (OR), and 95\% confidence interval (CI), are given. For continuous variables, OR represents the factor by which the odds change when the variable increases by one unit; for dichotomous variables, it represents the factor by which the odds change for patients with a particular characteristic, as compared with those without the characteristic. Two-sided $P$ values of $<0.05$ were considered statistically significant (17). The statistical program used was SPSS for Windows, Version 9.0 (SPSS Inc., Chicago, IL, USA).

\section{Results}

Patients' baseline clinical and laboratory data are reported in Table 1 . All patients showed clinical severe impairment, as reflected by the APACHE II score, and derangement of pulmonary gas exchange. No patient had blood test results suggestive of cachexia or of any other relevant metabolic disorder which could interfere with thyroid hormone metabolism.

Plasma levels of fT3 were below the lower limit of the normal range in 17 patients $(53 \%)$, and borderline low in $11(34 \%)$. Free T4 plasma concentrations were below the lower limit of the normal range in 3 patients only $(9 \%)$. TSH plasma levels were below the lower limit of the normal range in 10 patients (31\%), and were borderline low in 11 (34\%).

Plasma concentrations of fT3 were significantly correlated with the severity of pulmonary gas exchange impairment, as reflected by the $\mathrm{PaO}_{2} / \mathrm{FiO}_{2}$ ratio (Fig. 1A). A significant inverse correlation was found between fT3 levels and APACHE II score (Fig. 1B).

No statistically significant difference was observed between fT3 levels and age, sex and common metabolic parameters.

Four $(12.5 \%)$ of the 32 patients died during their stay in the respiratory intensive care unit. No significant 
(A)
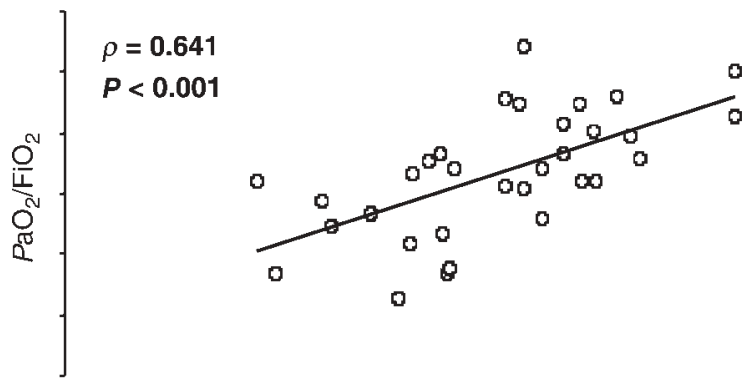

(B)

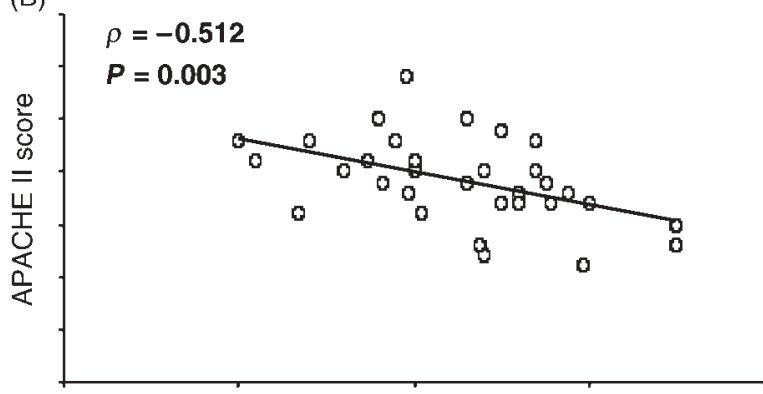

$\mathrm{fT} 3(\mathrm{pg} / \mathrm{ml})$

Figure 1 (A) Relationship between plasma levels of fT3 and the ratio of the partial pressure of oxygen in arterial blood to the fraction of oxygen in inspired gas $\left(\mathrm{PaO}_{2} / \mathrm{FiO}_{2}\right)$. (B) Relationship between plasma levels of fT3 and APACHE II score. Data were obtained in 32 patients with severe respiratory failure upon admission to the respiratory intensive care unit.

difference was observed between these patients and those who survived as to age, clinical status reflected by APACHE II score, pulmonary gas exchange and metabolic parameters. Conversely, plasma fT3 levels were significantly lower $(P=0.002)$ in patients who died (median fT3 $1.41 \mathrm{pg} / \mathrm{ml}$; range, $1.00-1.82 \mathrm{pg} / \mathrm{ml}$ ) than in those who survived (median fT3, $2.40 \mathrm{pg} / \mathrm{ml}$; range, $1.34-3.50 \mathrm{pg} / \mathrm{ml}$ ). In a univariate logistic regression analysis, fT 3 was the only factor significantly associated with an increased risk of death (OR, 64.23; 95\% CI, 1.78-2316.86; $P=0.023$ ) (Table 2).

Thyroid parameters tended to return to normal levels at the time of discharge from the respiratory intensive care unit. The median fT3 upon admission was $2.33 \mathrm{pg} / \mathrm{ml}$ (range, $1.00-3.50 \mathrm{pg} / \mathrm{ml}$ ), and it was $2.72 \mathrm{pg} / \mathrm{ml}$ (range, 2.30-5.31 pg/ml) at discharge $(P=0.002)$. In this study sample, there was a significant correlation between the percent increase in fT3 levels and the percent increase in $\mathrm{PaO}_{2} / \mathrm{FiO}_{2}$ ratio $(\rho=0.578 ; P=0.015)$.

The median TSH at discharge $(1.070 \mu \mathrm{IU} / \mathrm{ml})$ was higher than the median TSH observed at admission $(0.634 \mathrm{IU} / \mathrm{ml})$, but the increase was not statistically significant $(P=0.3259)$ in the nonparametric pairedsamples Wilcoxon test. The median of fT4 $(1,29 \mathrm{ng} / \mathrm{dl})$ at admission was similar to the median
Table 2 Univariate logistic regression analysis.

\begin{tabular}{lrll}
\hline & OR & \multicolumn{1}{c}{$95 \% \mathbf{C l}$} & $\boldsymbol{P}$ \\
\hline $\mathrm{fT} 3$ & 64.23 & $1.78-2316.86$ & 0.023 \\
$\mathrm{fT} 4$ & 22.99 & $0.71-745.33$ & 0.077 \\
$\mathrm{TSH}$ & 0.66 & $0.17-2.54$ & 0.542 \\
$\mathrm{Age}$ & 1.06 & $0.95-1.18$ & 0.303 \\
$\mathrm{Sex}$ (male) & 1.33 & $0.16-10.87$ & 0.788 \\
$\mathrm{APACHE}$ II score & 0.87 & $0.67-1.15$ & 0.334 \\
$\mathrm{PaCO}_{2}$ & 1.01 & $0.96-1.07$ & 0.642 \\
$\mathrm{PaO}_{2}$ & 1.01 & $0.96-1.07$ & 0.707 \\
$\mathrm{PaO}_{2} /$ /FiO & & $0.99-1.05$ & 0.060 \\
$\mathrm{Cholesterolemia}_{\mathrm{Trigliceridemia}}$ & 0.03 & $0.96-1.01$ & 0.320 \\
$\mathrm{Protidemia}_{\mathrm{Glicemia}}$ & 1.01 & $0.98-1.03$ & 0.746 \\
Creatininemia & 3.49 & $0.62-19.61$ & 0.155 \\
& 1.00 & $0.97-1.03$ & 0.969 \\
\hline
\end{tabular}

of fT4 at discharge $(1.28 \mathrm{ng} / \mathrm{dl})$, and was not statistically significant.

\section{Discussion}

Various low T3 states have long been reported in a variety of severe acute and chronic diseases. For many years, this phenomenon has been considered as a transient adaptive process, but there is increasing evidence that an induced hypothyroid-like state may in itself worsen the patient's clinical status (3).

In our study, reduced fT3 levels were found in most patients with respiratory failure due to respiratory disorders. Plasma levels of fT4 were not reduced, and TSH levels varied at baseline from normal to reduced when compared with the normal range, as observed in patients with severe nonthyroidal diseases (3). Plasma levels of fT3 were related to clinical status and pulmonary gas exchange impairment, as reflected by APACHE II score and $\mathrm{PaO}_{2} / \mathrm{FiO}_{2}$ ratio respectively. Furthermore, the normalization of fT3 levels was associated with an improvement in gas exchange.

It has been suggested that fT3 levels may be a reliable predictor of clinical outcome (18). In patients undergoing cardiac surgery, fT3 levels did correlate with the time spent in intensive care unit, taken as an index of the overall clinical outcome (19). A recent report (20) found a strong correlation between low T3 state and the long-term prognosis in patients with various cardiovascular disorders.

In our study, patients who died had significantly lower fT3 levels than those who survived. Conversely, there was no significant difference between the two groups of patients in terms of age, sex, metabolic parameters, APACHE II score and severity of gas exchange impairment.

Reduced fT3 levels were also found as the only significant predictor of death in univariate logistic regression analysis, because, in spite of only four 
deaths and large CI, the OR is higher by one unit and therefore statistically significant.

In conclusion, the preliminary data of our study suggest that fT3 plasma concentration may be used as a marker of disease severity in patients with respiratory failure due to pulmonary disorders. Given the small size of our study sample, it is still unclear whether the low T3 state represents only a biochemical prognostic marker or whether it actually contributes to the development and progression of respiratory failure. Nevertheless, the role of fT3 concentration (that is, $<2.3 \mathrm{pg} / \mathrm{ml}$ ) as a potential prognostic marker in respiratory patients is not surprising in view of its importance in maintaining the homeostasis of almost all organ systems, and its role in modulating systemic adaptations to acute injury. In this regard, fT3 could be more useful than systemic (APACHE II score) and organspecific $\left(\mathrm{PaO}_{2} / \mathrm{FiO}_{2}\right.$ ratio) functional parameters as an additional predictor of outcome.

\section{Acknowledgements}

We thank the medical and paramedical staff of our institution for their contribution to this study. We thank Massimo Miniati, MD, for his helpful comment and critical review of this paper. We would like to express our gratitude to Eugenio Pacifico, MD, Ms Ceccobelli Eliana, Ms Cristina Chiurulla and Ms Fastellini Roberta for their most valuable laboratory assistance. We would like also to thank Ms Eva Tikotin and Mr Lucio Bruni for, respectively, their skilful secretarial and technical assistance.

\section{References}

1 Camacho PM \& Dwarkanathan AA. Sick euthyroid syndrome. What to do when thyroid function tests are abnormal in critically ill patients. Postgraduate Medicine 1999105 215-219.

2 Kelly GS. Peripheral metabolism of thyroid hormones: a review. Alternative Medicine Review 20005 306-333.

3 Chopra IJ. Euthyroid sick syndrome: is it a misnomer? Journal of Clinical Endocrinology and Metabolism 199782 329-334.

4 Henneman G, Docter R \& Krenning EP. Causes and effects of the low T3 syndrome during caloric deprivation and non-thyroidal illness: an overview. Acta Med Austriaca $19881542-45$.

5 Monig H, Arendt T, Meyer M, Kloehn S \& Bewig B. Activation of the hypothalamo-pituitary-adrenal axis in response to septic or non-septic diseases - implications for the euthyroid sick syndrome. Intensive Care Medicine 199925 1402-1406.

6 Cherem HJ, Nellen HH, Barabejski FG, Chong MBA \& Lifshitz GA. Thyroid function and abdominal surgery. A longitudinal study. Archives of Medical Research 199223 143-147.

7 Vardarli I, Schmidt R, Wdowinski JM, Teuber J, Schwedes U \& Usadel KH. The hypothalamo-hypophyseal thyroid axis, plasma protein concentration and the hypophyseogonadal axis in low T3 syndrome following acute myocardial infarct. Klinische Wochenschrift 198765 129-133.

8 Hamilton MA, Stevenson LW, Lun M \& Walden JA. Altered thyroid hormone metabolism in advanced heart failure. Journal of the American College of Cardiology 199016 91-95.

9 Holland FW, Brown PS, Weintraub BD \& Clark RE. Cardiopulmonary bypass and thyroid function: a 'euthyroid sick syndrome'. Annals of Thoracic Surgery 199152 46-50.

10 Vexiau P, Perez-Castiglioni P, Socie G, Devergie A, Toubert ME, Aractingi S \& Gluckman E. The 'euthyroid sick syndrome': incidence, risk factors and prognostic value soon after allogeneic bone marrow transplantation. British Journal of Hematology $199385778-782$.

11 Kaptein EM. Clinical relevance of thyroid hormone alterations in non-thyroidal illness. Thyroid International $1997422-25$.

12 Chow CC, Mak TW, Chan CH \& Cockram CS. Euthyroid sick syndrome in pulmonary tuberculosis before and after treatment. Annals of Clinical Biochemistry 199532 385-391.

13 Kawakami M, Usami I, Kuroki H \& Goto M. Thyroid hormones in patients with clinical stable pneumoconiosis. Nihon Kyobu Shikkan Gakkai Zasshi 199331 1215-1219.

14 Wawrzynska L, Sakowicz A \& Filipecki S. Euthyroid sick syndrome in patients with respiratory failure. Pneumonologia i Alergologia Polska 199664 (S2) 193-199.

15 Okutan O, Kartaloglu Z, Onde ME, Bozkanat E \& Kunter E. Pulmonary function tests and thyroid hormone concentrations in patients with chronic obstructive pulmonary disease. Medical Principles and Practice 200413 126-128.

16 Knaus WA, Draper EA, Wagner DP \& Zimmerman JE. APACHE II: A severity of disease classification system. Critical Care Medicine $198513818-829$.

17 Glantz SA. Primer of Biostatistics. New York: McGraw-Hill, 1987.

18 Klein I \& Ojamaa K. Thyroid hormone and the cardiovascular system. New England Journal of Medicine 2001 344 501-509.

19 Sabatino L, Cerillo AG, Ripoli A, Pilo A, Glauber M \& Iervasi G. Is the low tri-iodothyronine state a crucial factor in determining the outcome of coronary artery bypass patients? Evidence from a clinical pilot study. Journal of Endocrinology 2002175 577-586.

20 Iervasi G, Pingitore A, Landi P, Raciti M, Ripoli A, Scarlattini M, L'Abbate A \& Donato L. Low-T3 syndrome a strong prognostic predictor of death in patients with heart disease. Circulation $2003107708-713$.

Received 31 March 2004

Accepted 20 August 2004 